\title{
Polyacetylene-Based Polyelectrolyte as a Universal Interfacial Layer for Efficient Inverted Polymer Solar Cells
}

Sungho Nam ${ }^{\mathrm{a}, \mathrm{b}}$, Jooyeok Seo ${ }^{\mathrm{a}}$, Myeonghun Song ${ }^{\mathrm{a}}$, Hwajeong Kim ${ }^{\mathrm{a}, \mathrm{c}}$, Moonhor Ree ${ }^{\mathrm{c}}$, Yeong-Soon Gal ${ }^{\mathrm{e}}$,

Donal D. C. Bradley,f, and Youngkyoo Kim ${ }^{\mathrm{a}, *}$

${ }^{a}$ Organic Nanoelectronics Laboratory and KNU Institute for Nanophotonics Applications, Department of Chemical Engineering, School of Applied Chemical Engineering, Kyungpook National University, Daegu 41566, Republic of Korea

${ }^{b}$ Departments of Physics, Division of Mathematical, Physical and Life Sciences, University of Oxford, Oxford OX1 3PU, United Kingdom

'Priority Research Center, Research Institute of Advanced Energy Technology, Kyungpook National University, Daegu 41566, Republic of Korea

${ }^{d}$ Department of Chemistry and Division of Advanced Materials Science, Pohang University of Science and Technology, Pohang 37673, Republic of Korea

${ }^{e}$ Polymer Chemistry Laboratory, College of Engineering, Kyungil University, Gyeongsan 38428, Republic of Korea

${ }^{f}$ Department of Engineering Science, Division of Mathematical, Physical and Life Sciences, University of Oxford, Oxford OX1 3PJ, United Kingdom

*Corresponding author: Prof. Y. Kim (E-mail addresses: ykimm@knu.ac.kr) 


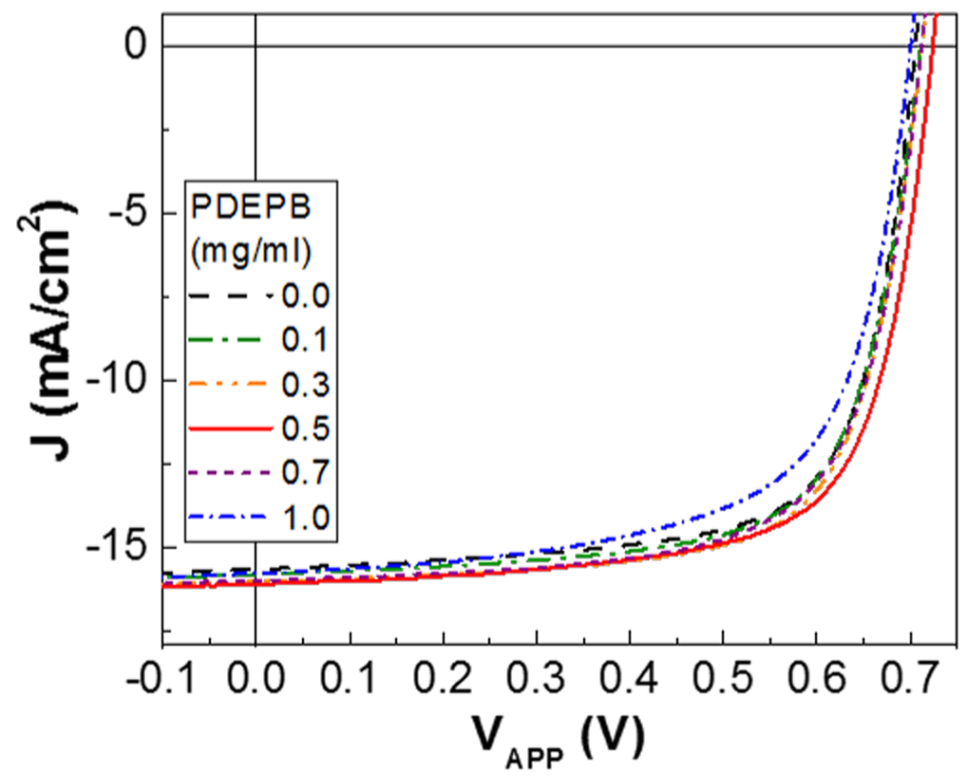

FIG. S1. Light (air mass $1.5 \mathrm{G}, 100 \mathrm{~mW} / \mathrm{cm}^{2}$ ) $\mathrm{J}-\mathrm{V}$ curves for the inverted-type PTB7:PC ${ }_{71} \mathrm{BM}$ solar cells with the PDEPB interlayers according to the various PDEPB solution concentrations.
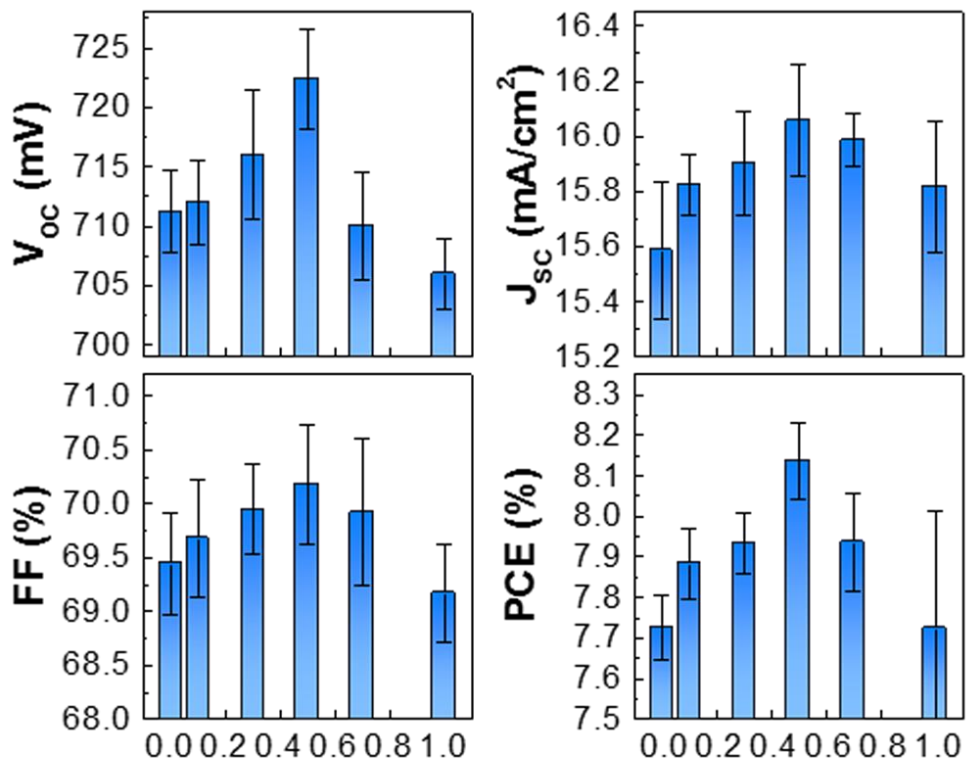

PDEPB Solution Concentration $(\mathrm{mg} / \mathrm{ml})$

FIG. S2. Solar cell parameters as a function of PDEPB solution concentration. 


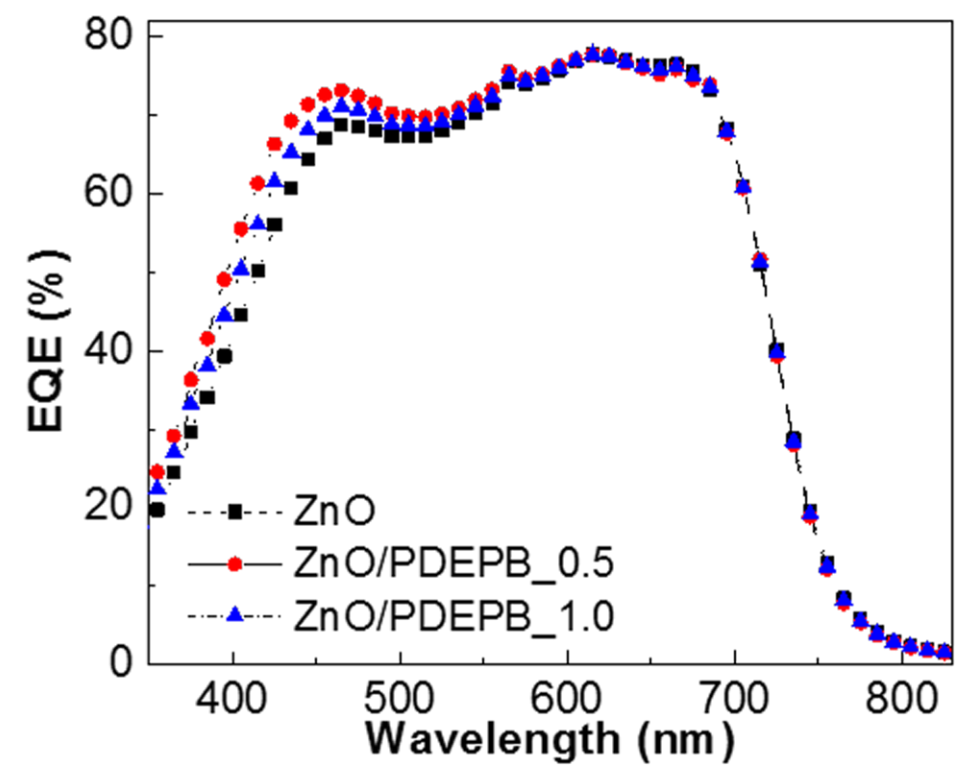

FIG. S3. EQE spectra for the inverted-type PTB7:PC ${ }_{71} \mathrm{BM}$ solar cells with the PDEPB interlayers according to the PDEPB solution concentrations: $0 \mathrm{mg} / \mathrm{ml}(\mathrm{ZnO}), 0.5 \mathrm{mg} / \mathrm{ml}\left(\mathrm{ZnO} / \mathrm{PDEPB} \_0.5\right)$, and $1.0 \mathrm{mg} / \mathrm{ml}$ (ZnO/PDEPB_1.0).

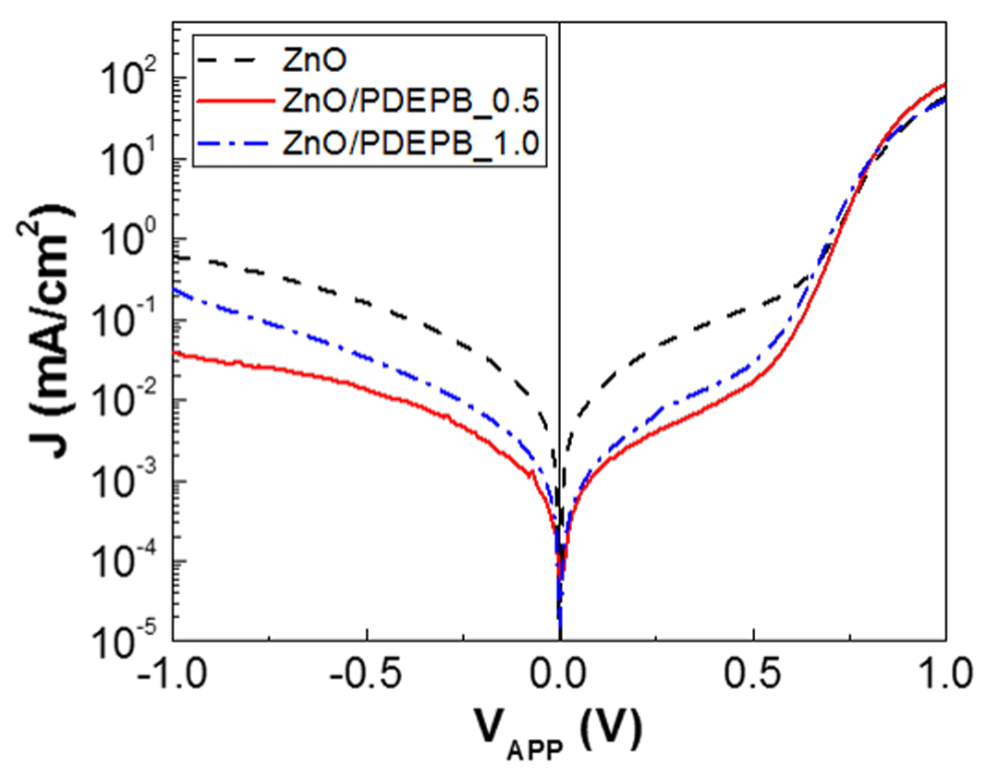

FIG. S4. Dark J-V curves for the inverted-type PTB7:PC 71 BM solar cells according to the PDEPB concentration: $0 \mathrm{mg} / \mathrm{ml}(\mathrm{ZnO}), 0.5 \mathrm{mg} / \mathrm{ml}\left(\mathrm{ZnO} / \mathrm{PDEPB} \_0.5\right)$, and $1.0 \mathrm{mg} / \mathrm{ml}$ (ZnO/PDEPB_1.0). 


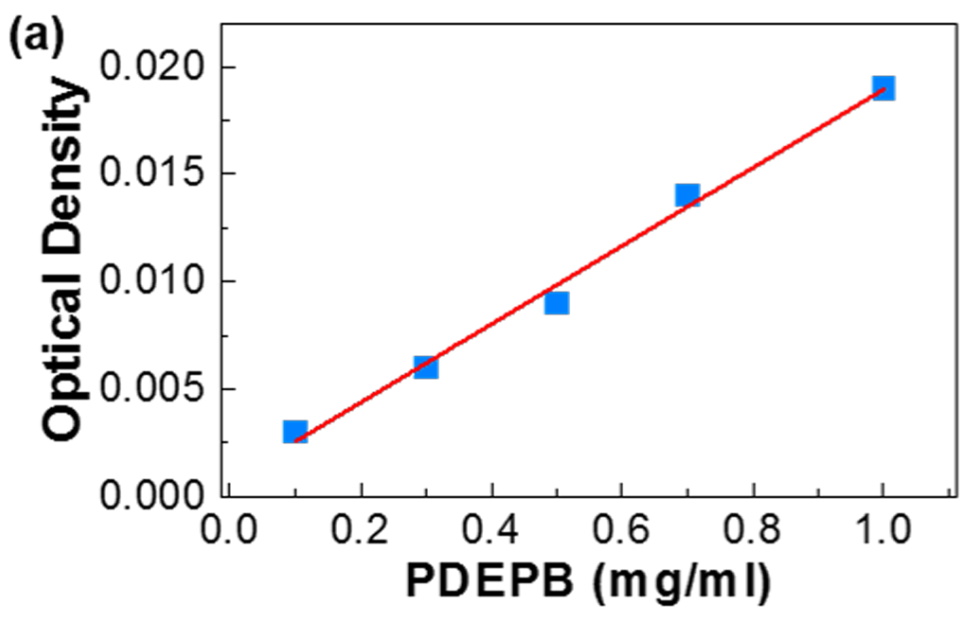

(b)

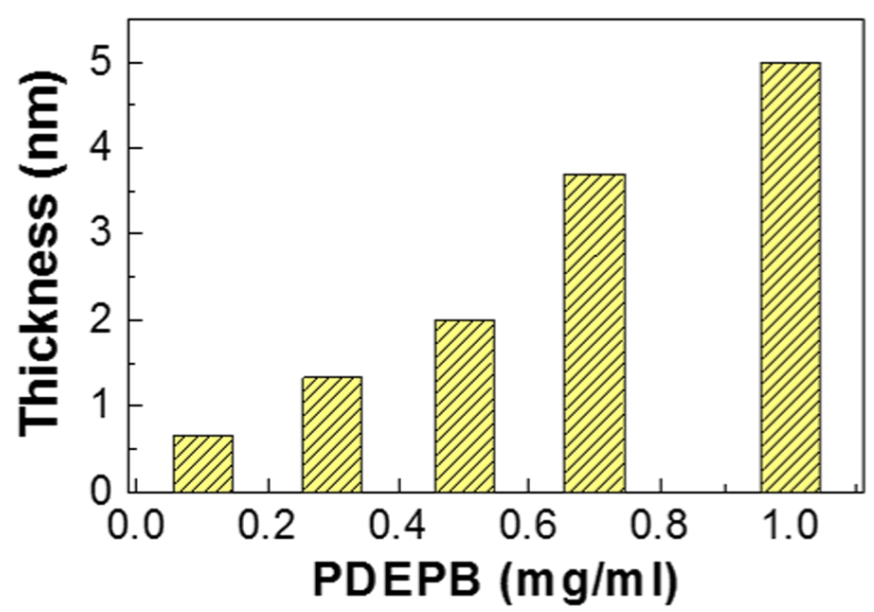

FIG. S5. (a) Optical density and (b) film thickness estimated by optical density as a function of PDEPB solution concentration 